\title{
Cyst-Gastrostomy via the Cyst: An Unusual Laparoscopic Approach
}

A 55-year-old woman with chronic pancreatitis was admitted to hospital with abdominal pain. Ultrasound identified a large cyst in the upper abdomen. A computed tomography (CT) scan confirmed a pancreatic pseudocyst, which extended over the lesser curve and lay predominantly anterior to the stomach. It also involved the splenic hilum and showed evidence of a recent bleed (Figure 1). Angiography showed patent splenic vessels and no evidence of active bleeding. The patient was initially treated conservatively, but magnetic resonance imaging (MRI) showed that the cyst was enlarging. Laparoscopic exploration was undertaken.

Pneumoperitoneum was established and the primary cannula was inserted below the cyst. Under direct vision, $10-\mathrm{mm}$ cannulae were inserted into the cystic cavity, releasing 31 of turbid brown fluid. Examination of the interior of the cyst revealed an area of old clot near the splenic hilum. It was left undisturbed. With a flexible endoscope transilluminating the anterior stomach wall, a 2.5-cm cyst-gastrostomy was formed using ultrasonic shears (Figure 2).

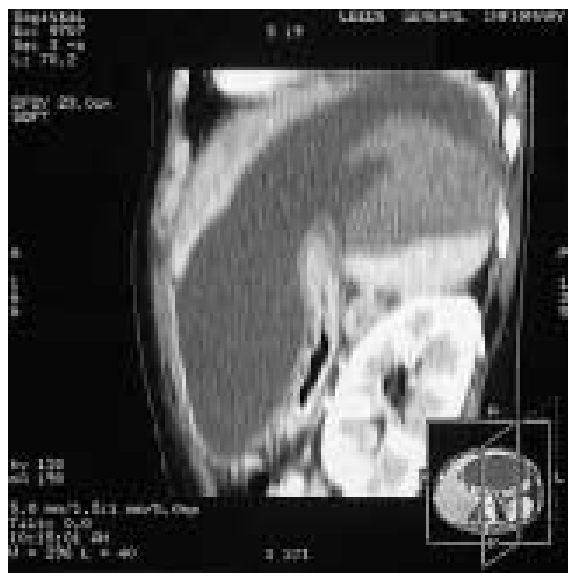

Figure 1 The sagittal reconstruction of the computed tomography (CT) scan demonstrates the anatomical relationship of the pseudocyst to the stomach. Evidence of a recent bleed is clearly visible in the retrogastric portion
Diet was recommenced on day 4. The postoperative stay (16 days) was prolonged due to opiate withdrawal symptoms but otherwise, recovery was unremarkable. Repeat MRI before discharge showed complete resolution of the pseudocyst, and the patient remained clinically well 1 year later. She was lost to subsequent follow-up.

Pancreatic pseudocysts occur in 20-40\% of cases of chronic pancreatitis [1]. Most develop within or anterior to the pancreas but posterior to the stomach. There are reports of unusual pseudocysts that involve the spleen or cause retrocardiac compression [2,3], but it is unusual for pseudocysts to lie anterior to the stomach. The single case identified in the literature was treated by laparotomy and insertion of an external drain. A pancreatic fistula resulted [4]. Laparoscopic cyst-gastrostomy is now routine in our unit, usually accomplished by an intragastric technique [5]. Modification of the technique to an intracystic approach, with endoscopic assistance, was successful for this unusual case.

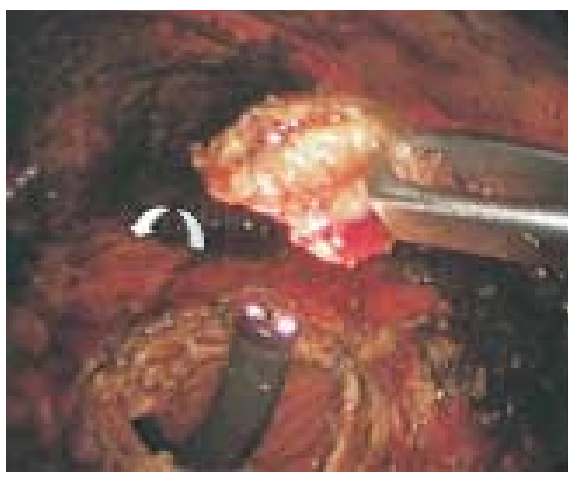

Figure 2 View from within the cystic cavity, demonstrating the anterior gastrostomy which was fashioned after endoscopic location of an optimal access site. In the background, the pseudocyst is seen to extend from behind the stomach and over the lesser curve (arrow)

\section{W. G. Ainslie, M. Larvin, M. J. McMahon} Leeds Institute for Minimally Invasive Therapy (LIMIT), and Academic Unit of Surgery, The General Infirmary at Leeds, Leeds, UK

\section{References}

${ }^{1}$ Grace PA, Williamson RCN. Modern management of pseudocysts. Br J Surg 1993; 80: 573 - 581

${ }^{2}$ Fishman EK, Soyer P, Bliss DF et al. Splenic involvement in pancreatitis: Spectrum of CT findings. AJR Am J Roentgenol 1995; 164: 631-635

${ }^{3}$ Shah A, Schwartz H. Echocardiographic feature of cardiac compression by mediastinal pancreatic pseudocyst. Chest 1980; 77: 440-443

${ }^{4}$ Mabogunje OA. Pseudocysts of the pancreas in children: an African series. Ann Trop Paediatr 1988; 8: 241 - 243

${ }^{5}$ Ainslie WG, Ammori BJ, Larvin M, McMahon MJ. An initial experience of laparoscopic pseudocyst drainage. Surg Endosc 2001; 15: S105

\section{Corresponding Author}

\section{W. G. Ainslie, M.B. Ch.B.}

Leeds Institute

for Minimally Invasive Therapy (LIMIT), and Academic Unit of Surgery

6th Floor Wellcome Wing

The General Infirmary at Leeds

Great George St

Leeds LS1 3EX

UK

Fax: + 44-113-3926305

E-mail: wgainslie@btinternet.com 